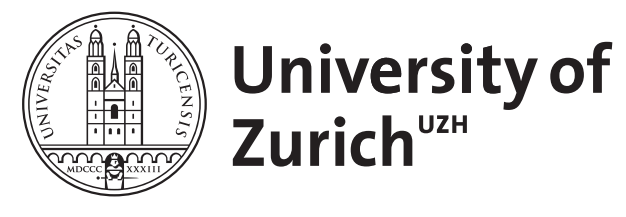

\title{
The effects of time delay in reciprocity games
}

\author{
Neo, Wei Siong ; Yu, Michael ; Weber, Roberto A ; Gonzalez, Cleotilde
}

\begin{abstract}
Reciprocity is common in economic and social domains, and it has been widely documented in the laboratory. While positive and negative reciprocity are observed in investment and ultimatum games, respectively, prior laboratory studies often neglect the effect of time delays that are common in real-world interactions. This research investigates the effect of time delays on reciprocity in the investment and ultimatum games. We manipulate the time delay after second movers have been informed about the first movers' decisions. We find that a delay is correlated with fewer rejections in the ultimatum game, but we find no effect of delays in the investment game. A follow-up study explores some of the processes that occur during time delay in the ultimatum game. We find delays correlated to increased reported feelings of satisfaction and decreased reported feelings of disappointment. Increased satisfaction is correlated to an increased probability of rejection, while disappointment has a more complex relationship to the probability of rejection.
\end{abstract}

DOI: https://doi.org/10.1016/j.joep.2012.11.001

Posted at the Zurich Open Repository and Archive, University of Zurich

ZORA URL: https://doi.org/10.5167/uzh-73679

Journal Article

Accepted Version

Originally published at:

Neo, Wei Siong; Yu, Michael; Weber, Roberto A; Gonzalez, Cleotilde (2013). The effects of time delay in reciprocity games. Journal of Economic Psychology, 34:20-35.

DOI: https://doi.org/10.1016/j.joep.2012.11.001 


\title{
The Effects of Time Delay in Reciprocity Games
}

\author{
Wei Siong $\mathrm{Neo}^{1}$, Michael $\mathrm{Yu}^{1}$, Roberto A. Weber ${ }^{2}$, Cleotilde Gonzalez ${ }^{1}$ \\ ${ }^{1}$ Department of Social and Decision Sciences \\ Carnegie Mellon University \\ ${ }^{2}$ Department of Economics \\ University of Zurich
}

August 13, 2012

Corresponding Author: Cleotilde Gonzalez, coty@cmu.edu 


\begin{abstract}
Reciprocity is common in economic and social domains, and it has been widely documented in the laboratory. While positive and negative reciprocity are observed in investment and ultimatum games, respectively, prior laboratory studies often neglect the effect of time delays that are common in real-world interactions. This research investigates the effect of time delays on reciprocity in the investment and ultimatum games. We manipulate the time delay after second movers have been informed about the first movers' decisions. We find that a delay is correlated with fewer rejections in the ultimatum game, but we find no effect of delays in the investment game. A follow-up study explores some of the processes that occur during time delay in the ultimatum game. We find delays correlated to increased reported feelings of satisfaction and decreased reported feelings of disappointment. Increased satisfaction is correlated to an increased probability of rejection, while disappointment has a more complex relationship to the probability of rejection.
\end{abstract}

Keywords: reciprocity; time delay; ultimatum game; investment game; emotions

Index Classification: reciprocity, game theory

PsycINFO Classification: 3020

JEL-Classification: C70, D63 


\section{Introduction}

Over the last 20 years, many studies have found evidence of behaviors consistent with reciprocity - the act of responding to perceived kindness with kindness and perceived unkindness with retaliation (Fehr \& Fischbacher, 2002; Cox, Friedman, \& Gjerstad, 2007). Economists have studied its role in sustaining social norms, enforcing incomplete contracts, and producing downward wage rigidity (Fehr \& Gächter, 2000). In the field, psychologists found that a waitress with a broad smile receives greater tips (Tidd \& Lockard, 1978), while economists have found that kind acts are rewarded in the context of charitable donations (Falk, 2007). Both economists and psychologists have also found negative reciprocity, for example, in the context of wage cuts (Greenberg, 1990; Kube, Marechal \& Puppe, 2010). Several theoretical models complement these investigations (e.g., Cox et al., 2007; Dufwenberg \& Kirchsteiger, 2004; Falk \& Fischbacher, 2006). These models capture the idea of reciprocity and predict behavior consistent with observations in these experiments.

In the laboratory, the investment game (IG) is often used to study positive reciprocity. The first move, known as the sender, chooses how much money to give to the second mover, known as the receiver. Any money sent is increased by the experimenter. The responder then decides whether to return any money to the sender. Backward induction predicts that the responder will return nothing and thus the sender should send nothing. However, numerous studies show that most responders provide positive returns after reciving positive transfers from senders (Berg, Dickhaut \& McCabe, 1995).

The ultimatum game (UG) is often used to study negative reciprocity. The first mover, known as the proposer, offers a division of money between herself and the second mover, known 
as the responder. The responder either accepts or rejects the offer. If the responder accepts, the money is split according to the proposal; if the responder rejects, the proposer and the responder both receive nothing. Backward induction predicts that the responder should accept any positive offer and thus the proposer should offer the smallest possible positive amount. However, numerous studies demonstrate that most proposers offer $25 \%$ to $50 \%$ of the money, and that responders reject proposals half of the time when the offers are less than $20 \%$ of the money being divided (see Camerer, 2003, for a review).

In this paper, we explore one aspect often found in the field, but not in the laboratory, time delay. We study its effects by varying whether the responders' decisions in the IG and UG are made either immediately after finding out the first movers' decisions or waiting until after finding out the first movers' decision before making their own. We address several questions relating to the influence of time delay and reciprocity. First, does time delay have any effect on second movers' strategic behavior in the IG and UG? Second, do first movers anticipate potential effects of time delay and adapt their strategic behavior accordingly? Finally, what processes during the time delay cause these effects? These questions are answered in three experiments. In Section 2, we briefly summarize the related literature. Section 3 describes how time delay may affect reciprocity and explains our predictions. In Sections 4, 5, and 6, we present the design, procedures, and results of our IG and UG experiments. Section 7 discusses our empirical findings, highlights some future research directions, and concludes.

\section{Time delay in reciprocity games}

To the best of our knowledge, only three studies have empirically examined time delay in reciprocity games. First, Bosman, Sonnemans, and Zeelenberg (2001) conjectured that time 
delay would lead responders in the UG to experience less intense negative emotions when making their decisions, which would be reflected in a lower rejection rate. In both baseline and "cool-off" treatments, proposers suggested how to divide 20 Dutch guilders; responders in the former treatment decided whether to accept or reject their offers immediately after being informed, whereas responders in the latter treatment decided whether to accept or reject their offers an hour after being informed. In the basic treatment, 3 out of 16 offers (18.8\%) were rejected; in the cool-off treatment, 2 out of 22 offers (9.1\%) were rejected. When analyses were restricted to low offers, i.e., offers of less than half the money), 3 out of 10 offers (30.0\%) were rejected; in the cool-off treatment, 2 out of $19(10.5 \%)$ were rejected. Although it was in the hypothesized direction, the decreased rejection rate in the cool-off treatment was not statistically significant, regardless of the types of offers considered. This led the authors to conclude that time delay had no significant effect on the responders' behavior in the UG.

Second, Oechssler, Roider, and Schmitz (2008) predicted that time delay would result in a lower rejection rate in the UG. In the cash (lottery) treatment, proposers suggested how to divide 10 euros (lottery tickets - each with an equal probability of winning 500 euros); they could either offer 5 euros (tickets) or 2 euros (tickets) to responders. In both cash and lottery treatments, responders decided whether to accept or reject their offers immediately after being informed about them. After making their decisions, however, responders were notified that they would have an opportunity to revise their initial decisions. Twenty-four hours later, responders made their final decisions to accept or reject their offers. In the cash treatment, 45 out of 300 offers $(15.0 \%)$ were initially rejected and 40 offers (13.3\%) were rejected 24 hours later; in the lottery treatment, 36 out of 325 offers $(11.1 \%)$ were initially rejected and 25 offers $(7.7 \%)$ were 
rejected 24 hours later. When analyses were restricted to low offers (offers of 2 euros), in the cash treatment, 40 out of 94 offers $(42.55 \%)$ were initially rejected and $37(39.4 \%)$ were rejected 24 hours later; in the lottery treatment, 31 out of 112 offers (27.7\%) were initially rejected and $23(20.5 \%)$ were rejected 24 hours later. When analyses were restricted to the 2 euros (tickets) offers, time delay was correlated with significantly fewer rejections for the lottery treatment, but not for the cash treatment. This led the authors to conclude that time delay had no significant effect on the responders' behavior in the UG if low stakes were involved.

Third, Grimm and Mengel (2011) separated two methodological features from Oechssler et al.'s (2008) study: time delay and initial decisions. Proposers decided how to divide 10 Euros and the proposal was presented immediately to the responders. In the no delay treatment, responders could respond immediately to the proposal and then completed an approximately 10 minute questionnaire; in the delay treatment with no initial response, responders observed the proposal, completed the questionnaire, then decided whether to accept or reject; in the delay treatment with an initial response, responders observed the proposal, decided whether to accept or reject, completed the questionnaire, then decided whether to revise their decision. When restricted to very low offers ( 1 or 2 Euros), the authors find a significant difference between the no delay and the delay with no initial response treatments, but not between no delay and delay with an initial response; although aggregated statistics across all types of offers are not available.

\subsection{Contributions of our study}

Our first two experiment can be distinguished from the above three studies in two ways. First, while the previous studies focused only on negative reciprocity in the UG, our study uses two reciprocity games to test whether time delay has an effect on both positive and negative 
reciprocity. Second, while the effect of time delay on proposers' behaviors was not explicitly examined, our experiments are designed such that all participants are aware of the time delay so that changes in the first movers' behaviors can also be studied.

Additionally, given conflicting results from the previous three studies, our experiments hope to contribute to a more complete understanding regarding whether or not time delays have an effect on the UG. In particular, we suggest that the non-significant but directionally consistent findings of Bosman et al. (2001) and Oechssler et al. (2008) should not be over-interpreted. Bosman et al.'s (2001) study was limited by a small sample size and included rejection rates close to zero, over which tests for differences in binary outcomes are weak. With the Oechssler et al. (2008) study, we suggest that its directionally consistent results not be so quickly dismissed given the other studies discussed whose results are also directionally consistent. Our study questions whether these findings will still persist in replication and once one corrects for low

power. First, we employ the IG, where we can test the proportion of money returned by responders rather than a binary outcome. Second, we employ a variant of the UG with asymmetric payoffs, where the rejection rate is closer to $50 \%$ and where tests of binary outcomes have more power. Finally, our last experiment extends the work of the first two experiments, by looking more closely at the processes underlying time delay effects, focusing on measuring the degree to which reflective processing and emotions contribute to the potential effects of time delays.

\section{Predictions}

There are at least three ways in which time delay may influence reciprocity: (1) declining intensity of emotions, (2) increasing loss aversion, and (3) enhancing reflective processing. 


\subsection{Emotions}

Cox et al. (2007) include an explicit emotional state parameter in their model of reciprocity, suggesting that emotional states directly affect choice. In the IG, fMRI research has tied reward processing to benevolent sender's decisions in the IG (King Casas et al., 2005). In the UG, rejections are commonly believed to be caused by negative emotions, such as anger (Pillutla \& Murnigham, 1996), which is supported by fMRI research that finds greater activation in areas linked to processing anger and disgust (Sanfey et al., 2003).

Psychologists and economists have treated affective states as transitory (Forgas, 1991), and have found them to be subject to adaptation (Frederick \& Loewenstein,1999). After a time delay, responders may experience weaker emotions when making their decisions in the IG and UG, respectively, thus reducing reciprocal behavior. However, Frijda argues that repetition, not the passage of time, leads to reduced affective intensity (1988). As such, emotions felt at the time of the original offer may resurface, sustaining the reciprocal behavior.

\subsection{Loss aversion}

Loss aversion refers to the phenomenon where the loss of a fixed amount relative to a reference point is seen as qualitatively larger than gaining a similar amount (Kahneman \& Tversky, 1979). This has been used to explain the endowment effect, where an individual places a higher value on an object he/she owns compared to an identical object he/she does not own (Thaler, 1980). Kahneman, Knetsch, and Thaler (1990) presented compelling evidence for an instant endowment effect where object valuation was increased substantially upon possession and subsequent research has found that this valuation may increase over time (Strahilevitz \& Loewenstein, 1998). 
When responders receive an offer in the IG or are initially given money in the UG, they may see themselves as possessing that money. As time passes, their valuation of this money may increase, reducing reciprocal behavior.

\subsection{Reflective processing}

Dual-processing accounts of human behavior (see Evans, 2008 for a review) suggest that choice is determined by two distinct processing systems, which can account for economic behavior (Camerer, Loewenstein, \& Prelec, 2005). "System 1" involves automatic and intuitive processes that proceed relatively rapidly, whereas "System 2" involves controlled and reflective processes that proceed relatively slowly (Schneider \& Shiffrin, 1977; Shiffrin \& Schneider, 1977; Stanovich \& West, 2000). Notably "System 1" is associated not only with emotions (Epstein, 1994), but other forms of intuitive processing, such as heuristic reasoning.

Time delays should allow greater time for System 2 processing, thus leading to more economically rational decisions and reduced reciprocity. Previous research has looked at this aspect of reciprocity. Rubinstein (2008) found no differences in response times for accepting or rejecting UG offers, suggesting no differences in processing. However, this may have been confounded by individual differences. Cappelletti, Güth, and Ploner (2008) imposed exogenous time constraints, limiting System 2 processing, and found that participants under high time pressure (30s to respond) were more likely to reject offers than those under low time pressure (180s to respond).

\subsection{Predictions}

Overall, we expect that second movers, as a consequence of time delay, may experience weaker emotions, will be under the influence of stronger loss aversion, and will engage in more 
reflective processing. In the IG (UG), we expect that positive (negative) emotions triggered by trusting behavior (low offers) will diminish, attachment to the money sent (offered) will increase, and more reflective decisions that are likely to yield the subgame-perfect Nash equilibrium will be more likely. This translates to a lower proportion of money being returned (reduced likelihood of offers being rejected) by those responders who are making decisions after a time delay. We consider predictions for the two games separately, to account for the possibility that some of the mechanisms influencing IG would be different from those influencing UG.

Hypothesis 1: In the presence of time delay, while holding constant the first mover's behavior, a responder will return a lower proportion of money and will be less likely to reject offers in the $I G$ and $U G$, respectively.

The above prediction concerns the effect of time delay on second movers' behavior. How does time delay influence first movers' behavior? It is critical to recognize that in contrast to second movers, time delay does not have an experiential aspect for first movers. Rather, a first mover's behavior is affected to the degree that she strategically contemplates whether and how time delay will influence second movers' behavior and make adjustments accordingly. In the IG (UG), we expect that senders (proposers), who are aware that responders are making decisions after a time delay, will send (offer) less money in response to their expectation that those responders will return a lower proportion of money (are less likely to reject offers).

Hypothesis 2. When a time delay is involved, senders will send less money and proposers will offer less money in the IG and UG, respectively.

\section{Experiment 1: Positive reciprocity in the investment game (IG)}


The IG, often referred to as the "trust game," was first studied experimentally by Berg et al. (1995), and Van Huyck, Battalio, and Walters (1995), while a similar game was studied earlier by Camerer and Weigelt (1988). It is a two-player, sequential game that consists of two stages. One player is designated as the sender and the other player as the responder. The specific parameters that we adopted for our IG are described below.

At the beginning of the game, the sender and the responder were each endowed with $\$ 5$. In the first stage, the sender chose an integer amount $S$ in $[0,5]$ to send to the responder. Any positive amount $S$ was tripled by the experimenter so that the responder received the amount $3 S$. In the second stage, the responder decided an integer amount $R$ in $[0,5+3 S]$ to return to the sender. Thereafter, the game concluded and the final payoffs of the sender and the responder were $\$(5-S+R)$ and $\$(5+3 S-R)$, respectively. The traditional game theoretic prediction entails that $S=R=0$.

\subsection{Experimental Design}

Our design included two treatments (Immediate and Delay) that differed in terms of when responders selected how much money to return to their senders. The Immediate treatment corresponds to how the IG is typically implemented in the laboratory.

At the beginning of the experiment, general and game instructions were read aloud by an experimenter and simultaneously presented on personal computers in individual cubicles. The entire experiment was programmed and conducted with the z-Tree software (Fischbacher, 2007). Participants were randomly assigned to be senders or responders in the IG described above, and each sender was randomly and anonymously paired with a responder. It was emphasized that all 
participants would remain anonymous throughout the experiment and that the experiment involved a one-shot game.

In the Immediate treatment, the sender decided the integer amount $S$ to send. The responder was immediately informed of $S$ and $3 S$, and decided the integer amount $R$ to immediately return. The sender was immediately informed of $R$. Individual earnings from the game were revealed, indicating that the game had concluded. Thereafter, subjects were provided with 15 minutes of free time. Within the 15-minute period, participants were restricted from communicating or using any communication devices, but were otherwise not restricted in activity. When 15 minutes had elapsed, participants completed a questionnaire prior to the conclusion of the experiment.

In the Delay treatment, the sender decided the integer amount $S$ to send. The responder was immediately informed of $S$ and $3 S$, but as explained before the game began, would make his or her decision after a time delay. Thereafter, both movers were provided with 15 minutes of free time, as described above. After 15 minutes had elapsed, participants continued with the second stage of the IG. The responder decided the integer amount $R$ to return. The sender was immediately informed of $R$. Individual earnings from the game were revealed, indicating that the game had concluded. Participants then continued to the questionnaire.

Two aspects of our design warrant further mention. First, we provided participants in the Immediate treatment with 15 minutes of free time, even though that was not absolutely necessary; participants could have continued to the questionnaire immediately after playing the IG. This alternative design, however, implies that participants in the Immediate treatment will spend less time in the experiment and thus receive their earnings earlier. Our design, therefore, reduces 
potential concerns that may interfere with interpreting the contrasting behavior between the treatments.

Second, our time delay is rather short, and takes place entirely in the laboratory. In realworld interactions, several days or weeks may transpire and economic players may do many varied things during that time interval. However, our design is motivated by a desire to prevent communication between participants, which is difficult to do outside the laboratory. Given our very short and simple time delay manipulation, one might consider our results as offering the lower bound on the potential influences of lengthier and more natural time delays.

Participants were mainly students from Carnegie Mellon University and the University of Pittsburgh. A total of 66 individuals participated in the experiment: 17 and 16 pairs in the Immediate and Delay treatments, respectively. We conducted a total of four sessions, two for each treatment, and the number of pairs in a session ranged from seven to nine.

Participants received a show-up payment of $\$ 5$. In addition to their earnings in the IG, they also earned an additional $\$ 2$ for answering the demographics questions and a few questionnaires. All participants completed the experiment within an hour and earned, on average, $\$ 14.52$.

\subsection{Results}

Figures 1A and 1B depict the decisions of both senders and responders in the Immediate and Delay treatments, respectively. The data were first sorted by the amount sent by senders in increasing order, followed by the amount returned by responders in increasing order. The amounts sent, received, and returned are represented by open circles, vertical bars, and filled circles, respectively. This presentation of the data from the IG follows Berg et al.'s (1995) 
example. As the figures show, the amounts sent and returned in both Immediate and Delay

treatments varied considerably, but there appear to be no substantive differences between the two treatments.

Table 1 provides the summary statistics that allow a direct comparison between treatments, as well as information on participant demographics and the activities the participants reported doing (yes or no) during the 15 minute delay. On average, senders sent slightly more in the Delay treatment $(\$ 2.63)$ than in the Immediate treatment $(\$ 2.41)$, but this did not differ significantly. On average, responders returned similar amounts without (\$1.76) and with (\$1.81) time delay. The proportion of money returned by responders is defined as the amount returned divided by the amount received (i.e., $R / 3 S$ ); this statistic is indeterminate for the six responders whose senders sent nothing. From Table 1, the mean proportions of money returned in both treatments were nearly identical $(0.24$ and 0.23 in the Immediate and Delay treatments respectively), providing further evidence that the responders' behavior was not influenced by time delay.

Table 2 reports the OLS regressions of the amount sent (Model 1) and the amount returned by responders (Models 2 and 3). For the latter two models, only those cases in which the sender sent a positive amount were used. Model 1 confirms that there was no treatment effect on the senders' behavior. In Models 2 and 3, the amount returned is increasing in the amount 
received, which provides evidence of reciprocity. ${ }^{1}$ But the Delay treatment has no effect on the amount returned. ${ }^{2}$

These low proportions of money returned implied that senders, on average, were suffering monetary losses. Table 1 shows that senders in the Immediate and Delay treatments earned $\$ 4.35$ and $\$ 4.19$ respectively, which is less than what they would have earned if they simply pocketed their $\$ 5$ endowment at the beginning of the game. On the other hand, responders in the Immediate and Delay treatments earned \$10.47 and \$11.06 respectively, which included their $\$ 5$ endowment at the beginning of the game. The amounts earned by the two roles did not differ significantly by treatment. ${ }^{3}$

\subsection{Discussion}

Contrary to our hypotheses, we find no effect of a time delay on behavior in the IG. The amounts sent by responders and the subsequent proportions returned are almost identical between the two treatments. The null result suggests that time delay - at least as implemented in this experiment - does not yield the hypothesized behavioral effects. Before drawing this conclusion, however, we explore behavior in the ultimatum game.

\section{Experiment 2: Negative reciprocity in the ultimatum game (UG)}

\footnotetext{
${ }^{1}$ An alternative interpretation is that responders are simply able to return more money when they receive more. However, Figure 1 reveals that none of the responders used in the regressions in Table 2 returned the maximum amount to the sender.

${ }^{2}$ We do not include an interaction term between amount received and Delay treatment because of the high collinearity between the interaction and the Delay treatment variable (the correlation is 0.76 ). Including the interaction term does not substantively change the results. Replacing Delay treatment with the interaction term also does not change the results.

${ }^{3}$ We found no significant relationship between the CRT and ZTPI questionnaire scores and subject behavior.
} 
The UG was first studied experimentally by Güth, Schmittberger, and Schwarze (1982). It is a two-player, sequential game that consists of two stages. One player is designated the proposer and the other player is designated the responder. Our specific implementation of the game involved asymmetric values for the good being divided. The specific parameters that we adopted are described below.

Our choice of a UG with asymmetric values was intended to circumvent the aforementioned power concerns in previous studies (Bosman et al., 2001; Oechssler et al., 2008). Recall that rejection rates in the baseline (no delay) conditions of these prior studies were quite low, potentially making it difficult to detect the effects of time delay, particularly if they are likely to reduce the rejection rate as hypothesized. Our design achieves a higher baseline rejection rate by introducing asymmetric values for the proposer and the responder. The UG used here is primarily informed by the experiment conducted by Kagel, Kim, and Moser (1996).

Kagel et al. (1996) varied both information and payoff structures to gain insight into the nature of fairness considerations in the UG. Of particular interest is the treatment where the proposer and the responder bargained over 100 chips and both had common knowledge that each chip was worth $\$ 0.30$ and $\$ 0.10$ to the proposer and the responder, respectively. Under such asymmetry, proposers and responders might be motivated by self-serving notions of fairness (Babcock \& Loewenstein, 1997; Thompson \& Loewenstein, 1992). ${ }^{4}$ Participants played that UG

\footnotetext{
${ }^{4}$ In this asymmetric UG, proposers benefit if fairness is interpreted as an equal division of chips rather than an equal division of money, while responders favor the alternative interpretation. Under an equal division of chips, the proposer receives 50 chips valued at $\$ 15$ and the responder receives 50 chips valued at $\$ 5$. Under an equal division of money, the proposer receives 25 chips valued at $\$ 7.50$, while the responder receives equal value from 75 chips.
} 
for 10 periods with perfect stranger matching. The authors reported a rejection rate of $39 \%$ across the 10 periods and a rejection rate of $52 \%$ for the first three periods. These rejection rates are much higher than that in the standard UG. ${ }^{5}$

\subsection{Experimental Design}

The procedures were almost identical to those employed for Experiment 1, except that we used the asymmetric UG described below instead of the IG. The treatment variable, time delay, was implemented as in Experiment 1.

Following general instructions, participants received instructions describing the UG. The proposer and the responder were informed that there were 100 chips to be divided between them and that each chip was worth $\$ 0.15$ to the proposer and $\$ 0.05$ to the responder. In the first stage, the proposer offered an integer number of chips $C$ in $[0,100]$ to the responder, thereby proposing to keep the remaining $(100-C)$ chips. In the second stage, the responder decided either to accept or reject the offer. If the responder accepted the offer, the proposer received $(100-C)$ chips valued at $\$(15-0.15 C)$, and the responder received $C$ chips valued at $\$ 0.05 C$; if the responder rejected the offer, neither the proposer nor the responder received any chips, and thus received no earnings. Thereafter, the game concluded.

A total of 86 individuals participated in the experiment: 22 and 21 pairs in the Immediate and Delay treatments, respectively. A total of six sessions, three for each treatment, was

\footnotetext{
${ }^{5}$ A more recent study, however, found lower rejection rates with the asymmetric UG (Gneezy \& Güth, 2003). In one of their treatments, the proposer and the responder bargained over 100 chips and both had common knowledge that each chip was worth $\$ 0.40$ and $\$ 0.20$ to the proposer and the responder respectively. Participants played that UG once and only 2 out of 16 offers (12.5\%) were rejected. The authors suggested that the dramatically lower rejection rate might be attributed to the less asymmetric ratio in chip values for their treatment.
} 
conducted and the number of pairs in a session ranged from six to nine. Recruitment and experimental procedures were identical to those in Experiment 1. We administered the same questionnaires from Experiment 1. Participants earned, on average, $\$ 10.54$.

\subsection{Results}

Figure 2 depicts the decisions by proposers and responders in each pair in the Immediate (Figure 2A) and Delay (Figure 2B) treatments of the UG. The data were first sorted by the number of chips offered by proposers in increasing order, followed by the responders' decisions with rejections displayed first. Offers accepted and rejected are represented by white and black vertical bars respectively. A summary of the data, by treatment and role, is presented in Table 3 .

The number of chips offered in both Immediate and Delay treatments varied considerably. Consistent with prior UG experiments and the notion of negative reciprocity, rejections typically occurred when the number of chips offered was relatively small. Comparing Figures $2 \mathrm{~A}$ and $2 \mathrm{~B}$, the frequency of rejections, considering all offers, was lower in the Delay treatment (14\%) than in the Immediate treatment (41\%), suggesting that the time delay influenced the responders' behavior as we predicted. The difference in the rejection frequencies is statistically significant in a non-parametric chi-square test $\left(\chi^{2}(1)=3.79, p=0.05\right)$.

Despite the lower rejection rate given a time delay, proposers offered similar numbers of chips, on average, in the Immediate (43.50) and Delay (45.81) treatments. Thus, responders did not appear to adjust for the responders' increased willingness to accept low offers given a time delay. This is confirmed in Model 1 of Table 4, which regresses the amount sent by proposers in the Delay treatment and demographic control variables, finding no significant relationships. 
Table 4 also confirms that responders were significantly less likely to reject offers in the Delay treatment. Models 2 and 3 reports the marginal effects coefficients for a probit regression of the responders' decisions to accept or reject. The negative coefficient for chips offered indicates reciprocity: responders were 1.4\% less likely to reject for every additional chip offered. According to Model 3 and consistent with our hypothesis, responders were $30 \%$ less likely to reject offers in the Delay treatment. ${ }^{6}$

The lower rejection rates in the Delay treatment suggests that both proposers and responders might have earned more money, on average, than their respective counterparts in the Immediate treatment. Table 3 shows that proposers in the Delay treatment earned $\$ 2.39$ more than those in the Immediate treatment, and this difference is statistically significant in a nonparametric rank-sum test $(\mathrm{z}=1.95, \mathrm{p}=0.05)$. Similarly, responders in the Delay condition earned $\$ 0.53$ more, on average, but this difference is not statistically significant.

\subsection{Discussion}

In Experiment 1, we did not find that time delay affected rejection rates in the IG; however, in Experiment 2, we found that time delay may lead to less rejections in the UG. A potential concern regarding the exogenously imposed time delay is that second movers in the Delay treatment may be susceptible to demand effects. In other words, they might wonder why their decisions were made 15 minutes later and hence reasoned that changes to their behavior

\footnotetext{
${ }^{6}$ As with Table 2, we do not include an interaction term between chips offered and Delay treatment because of the high collinearity between the interaction and the Delay treatment variable (the correlation is 0.87 ). Not surprisingly, including both the interaction term and the Delay treatment variable results in statistical insignificance for both coefficients. However, if we include only the interaction term (and not the Delay treatment variable), this coefficient is negative and similar in statistical significance to the Delay treatment variable in Model 3.
} 
were expected. The unintended null finding in the IG guards against this criticism to some extent because it is reasonable to assume that demand effects should be similar for both reciprocity games.

Previously, we presented three reasons why time delay might mitigate the tendency to behave reciprocally in the IG and UG: strengthened loss aversion/endowment effect, declining intensity of emotions, and reflective processing. The different effects of time delay across these two games provide stronger support for some of these reasons than others.

There is little reason for supposing that loss aversion/endowment effect's influence would differ between the reciprocity games. In both games, the responder should have become accustomed to a new reference point - possessing the offered money. As we find significant effects in the UG but not in the IG, we do not find strong support for loss aversion and the endowment effect.

On the other hand, there is some suggestion that reflective processing may account for the differences. At face value, responding to an UG offer involves a more straightforward decision than the IG. Research in the latter has shown that altruism, inequity aversion, and positive reciprocity all play a significant role in the responders' behavior (Charness \& Haruvy, 2002; Cox, 2004). Social and moral norms that differ across individuals, religions, and cultures have also been found to substantially influence the responders' behavior (Camerer, 2003). This inherent complexity may naturally induce more reflexive processing in the no delay treatment for IG, but not in the UG - leading to reduced differences in the IG when time delays are enforced. Our use of the asymmetric UG, under which there are multiple divisions of the initial endowment that may be considered fair, should increase the complexity of the UG and therefore reduce 
differences between our IG and UG experiments. Moreover, Oxoby and McLeish (2004) find no difference when participants are asked to consider responses to all possible offers prior to playing the UG (the strategy vector method) and when participants engage in the UG in the normal sequence; despite the greater reflexive processing imposed by the strategy vector method. Given these considerations, it seems that reflexive processing alone may not sufficiently explain our observed results.

Lastly, we find stronger support for the role of emotions. Previous research supports the hypothesis that the rejections of low offers in the UG are predominantly driven by negative emotions (Pillutla \& Murnighan, 1996; Sanfey et al., 2003); however, the diverse motivations of the responders' behavior in the IG just discussed may induce a less affective response. In addition, since senders are almost certainly sending money as a means to potentially gain more, some responders may not interpret transfers by senders as trusting behavior and consequently only experience relatively weak positive emotions, if any at all. Given the assortment of motivations underlying responder behavior in the IG and the less consequential role of positive emotions, the non-significant effect of time delay is no longer as perplexing. Moreover, the emotion explanation is also consistent with Oxoby and McLeish's (2004) study, if participants can anticipate their emotional responses to hypothetical scenarios (Mellers, Schwartz, \& Ritov, 1999; Robinson \& Clore 2001). We conjecture that the negative emotions produced by receiving a low offer in the UG, and which regularly leads to rejection in our Immediate treatment, diminish when the responder is forced to delay making a choice.

To better understand the contributions of these factors, we attempt to measure these in the UG in a third experiment. 


\section{Experiment 3: Processes of negative reciprocity with time delay in the ultimatum game (UG)}

Bosman et al. (2001) found that emotions appeared to play an important role in ultimatum game rejections. Specifically, negative emotions were correlated with lower offers; responders who expected higher offers reported more anger, irritation, and envy; and reports of anger, contempt, irritation, envy, and sadness were correlated with more rejections. However, they found no evidence of time delay affecting emotions and thus rejected emotional cooling off as a process that could affect ultimatum game behavior, and noted that emotions may "resurface" (Frijda, 1988) when responders in the time delay condition are asked to make their final decision.

Evidence from our Experiments 1 and 2 and continued concerns about statistical power prompted us to rerun the analysis with several modifications. First, we wanted to recruit a substantially larger sample. Second, we wanted to include emotions believed to be sensitive to more subtle changes in emotional states. For example, we suspected a scale point difference in "anger" may represent a bigger change in emotional state than a scale point difference in "frustration," and thus lead to reduced measurement precision and increased measurement error. Finally, research suggests that behavior in the ultimatum game can be affected by incidental emotions such as sadness (Harlé \& Sanfey 2007) and disgust (Bonini et al. 2011). To control for these effects, we wanted to ask participants to describe both their emotions when making the decision, as well as emotions experienced in the week prior to the experiment.

In addition, to measure reflective processing we asked responders to explain why they chose to accept or reject the offer. We use the length of their response in the form of a word count to assess the responder's reflective processing. 


\subsection{Experimental Design}

Procedures were similar to the asymmetric UG from Experiment 2. Immediately after responding to the offer, we asked responders to answer an open-ended question regarding why they chose to accept or reject the offer. Following the open-ended question, we asked responders "the extent to which [they] felt the following emotions when deciding how to respond to the offer" and "over the past week, not including during the survey." The emotions included: angry, frustrated, insulted, disappointed, happy, grateful, satisfied, confident, shocked, and surprised. Responses ranged from 1 ("Not at all") to 7 ("Extremely").

In addition, to increase our sample size, we administered the game online through Amazon mTurk. This required two notable changes in our design. First, while the proposer and responder were informed that 100 chips were to be divided between them, as before, each chip was now worth $\$ 0.03$ to the proposer and $\$ 0.01$ to the responder. These values were selected to be in line with the payments commonly given on mTurk. Second, as it was more difficult to monitor participants online, we provided participants with an unrelated task to perform during the 15 minute time delay in which participants had to interpret a graph describing the rate of people entering and leaving a department store. Performance in that task was not incentivized.

A total of 344 individuals completed the experiment: 88 and 84 pairs in the Immediate and Delay treatments, respectively. Recruitment was performed through Amazon mTurk. Participants were $53 \%$ male, had a median age of 25 , and predominantly resided in the United States $(73 \%)$ and India (22\%). In addition to their earnings in the UG, participants received a show-up payment of $\$ 1$. In total, participants earned, on average, $\$ 1.63$.

\subsection{Results}


Figure 3 depicts the decisions by proposers and responders in each pair in the Immediate (Figure 3A) and Delay (Figure 3B) treatments of the UG. Offers accepted and rejected are represented by white and black vertical bars respectively. A summary of the data, by treatment and role, is presented in Table 5. Comparing Figures $3 \mathrm{~A}$ and $3 \mathrm{~B}$, the frequency of rejections was lower in the Delay treatment $(25 \%)$ than in the Immediate treatment $(42 \%)$, suggesting that the time delay influenced the responders' behavior as predicted. The difference in the rejection frequencies is statistically significant in a non-parametric chi-square test $\left(\chi^{2}(1)=5.59, p=0.02\right)$.

In this experiment, we do see a suggestion that proposers may offer fewer chips in the Immediate (44.01) than in the Delay (50.00) treatments, although the significance is low. This difference is in the opposite direction as we had initially predicted.

In Models 2 and 3 of Table 5, we reproduce our findings that responders were less likely to reject offers in the Delay treatment, although the significance is lower than observed in Experiment 2. The negative coefficient for chips offered indicates reciprocity: responders were 1.2\% less likely to reject for every additional chip offered. According to Model 3 and consistent with our hypothesis, responders were $13 \%$ less likely to reject offers in the Delay treatment.

Models 4, 5, and 6 consider the contribution of emotion and reflexive processing. Model 4 was developed using all the emotion measures and word count, which we used to measure reflexive processing. Model 5 and Model 6 were determined using model selection that minimized AIC and BIC, respectively. Word count does not appear significantly correlated in Model 4 and the parameter is dropped by the model selection process in Models 5 and 6 . Three emotions appear correlated to rejections across all models: increased reports of insult and of confidence and decreased reports of satisfaction are correlated with increased rejection. In 
Models 4 and 5, decreased reports of disappointment are correlated with increased rejection. Reports of anger and frustration do not appear to have a significant effect on rejections. The effect of the delay treatment becomes non-significant in Models 4 and 5, and the delay treatment is removed as a dependent variable in Model 6.

Due to multicollinearity concerns, we also tested the effect of each emotion independently using independent probit regressions, with only demographic and treatment variables as covariates, included in Table 7. We find that increased reports of anger, frustration, injury, and shock and decreased reports of happiness, gratefulness, and satisfaction are correlated to increased rejections.

Table 8 considers the relationship between reflective processing and emotions to our treatments and demographic variables. Using an OLS regression, we find that larger offers are correlated with decreased reports of feeling angry, frustrated, insulted, disappointed, and shocked; and increased reports of feeling happy, grateful, satisfied, and surprised. The delay treatment is correlated with decreased reports of feeling disappointed and surprised; and increased reports of feeling satisfied. Reported feelings of each of these emotions over the past week are shown to significantly influence feelings at the time of the decision. Similar findings hold when running the analysis using an ordered logistic model. We also find that the delay treatment is correlated with longer explanations in the responders' decision.

\section{Discussion and conclusions}

In the IG, we found no significant evidence that time delay was correlated with either the senders' or the responders' behavior. In the UG, we found evidence that time delay was significantly correlated to decreased rejections by responders, and mixed evidence that time 
delay was correlated to more generous offers from the proposer. In the UG, we further found that time delay was correlated to increased reported satisfaction and decreased reported disappointment, with reported satisfaction appearing to partially mediate the effect of the reduced rejection and reported disappointment playing a potentially more complex role. In particular, disappointment was non-significantly correlated with increased probability of rejection when analyzed without other emotional covariates but with a decreased probability of rejection when other emotions were included. We suspect that this arises from two different sources of disappointment. The first source is from receiving a lower than expected offer and is captured by the other measures of emotion in our model. The second source is from conceding to a lower than expected offer.

A post hoc consideration of satisfaction and disappointment suggests an alternative to how time delay affects emotions. Both emotions are closely linked to meeting or failing to meet expectations. Bosman et al. (2001) found that responders who had expected higher offers reported more anger, irritation, and envy, which were all correlated with increased rejections of offers. In the time delay treatments, increased satisfaction and reduced disappointment may have resulted from reduced expectations. As such the reduced rejections may be attributed to a change in the emotional stimulus, rather than the waning of experienced emotions as suggested by traditional cooling off accounts.

We find little evidence of increased loss aversion or increased reflective processing as contributing to reduced rejections in the IG. For loss aversion, we would expect time delay to affect both the IG and UG; however, our experiments find an effect only in the UG, contrary to loss aversion predictions. For reflective processing, we do find evidence of greater reflective 
processing given a time delay in the form of longer explanations; however, longer explanations do not appear correlated with decreased rejections. Thus more thought about the decision does not appear to lead to more economically rational behavior.

Regarding the proposer in the UG, we found mixed evidence of the effect of time delay, with no significant effect in Experiment 2 and a marginally significant effect of more generous offers in Experiment 3. As such, we cannot conclusively state whether or not proposers change their behavior when faced with a time delay. If they do, Experiment 3 suggests that they respond in a way that is inconsistent with increasing their expected outcome.

However, we must be cautious about our conclusions given that our implementation of the UG and IG differ in more ways than the nature of the reciprocity. For example, the responders' decisions in our IG were almost continuous, whereas the responders' decisions in our UG were binary. Despite these differences, we believe that selecting variants of the UG and IG that are similar to previous research allows our findings to be more easily integrated and applied to what we currently know. With this as a basis, a greater understanding of the phenomenon can be developed by further varying how they time delay and the strategic games are implemented. 


\section{Acknowledgements}

This research was partially supported by the National Science Foundation (Human and Social Dynamics: Decision, Risk, and Uncertainty, Award number: 0624228) to Cleotilde Gonzalez. We are especially grateful to John Duffy and the University of Pittsburgh for providing access to the Pittsburgh Experimental Economics Laboratory (PEEL). Valuable comments by John Miller and Erte Xiao improved this paper and are much appreciated. 


\section{References}

Babcock, L., \& Loewenstein, G. (1997). Explaining bargaining impasse: The role of self-serving biases. Journal of Economic Perspectives, 11(1), 109-126.

Berg, J., Dickhaut, J., \& McCabe, K. (1995). Trust, reciprocity, and social history. Games and Economic Behavior, 10(1), 122-142.

Bonini, N., Hadjichristidis, C., Mazzocco, K, Demattè, M., Zampini, L., Massimiliano, S., Sbarbati, A., \& Magon, S. (2011) Pecunia olet: The role of incidental disgust in the ultimatum game. Emotion 11(4), 965-969.

Bosman, R., Sonnemans, J., \& Zeelenberg, M. (2001). Emotions, rejections, and cooling off in the ultimatum game. Unpublished manuscript. Retrieved from http://www1.fee.uva.nl/creed/pdffiles/coolingoff.pdf

Camerer, C. F. (2003). Behavioral game theory: Experiments in strategic interaction. Princeton, NJ: Princeton University Press.

Camerer, C., Loewenstein, G., \& Prelec, D. (2005). Neuroeconomics: How neuroscience can inform economics. Journal of Economic Literature, 43(1), 9-64.

Camerer, C., \& Weigelt, K. (1998). Experimental tests of a sequential equilibrium reputation model. Econometrica, 56(1), 1-36.

Cappelletti, D., Güth, W., \& Ploner, M. (2008). Being of two minds: An ultimatum experiment investigating affective processes. Jena Economic Research Papers, 2008-048.

Charness, G., \& Haruvy, E. (2002). Altruism, equity, and reciprocity in a gift-exchange experiment: An encompassing approach. Games and Economic Behavior, 40(2), 203-231.

Cox, J. C. (2004). How to identify trust and reciprocity. Games and Economic Behavior, 46(2), 260-281.

Cox, J. C., Friedman, D., \& Gjerstad, S. (2007). A tractable model of reciprocity and fairness. Games and Economic Behavior, 59(1), 17-45.

Dufwenberg, M., \& Kirchsteiger, G. (2004). A theory of sequential reciprocity. Games and Economic Behavior, 47(2), 268-298.

Evans, J. B. T. (2008). Dual-processing accounts of reasoning, judgment, and social cognition. Annual Review of Psychology, 59, 255-278.

Epstein, S. (1994). Integration of the cognitive and psychodynamic unconscious. American Psychologist, 49(8), 709-724.

Falk, A. (2007). Charitable giving as a gift exchange: Evidence from a field experiment. Econometrica, 75(5), 1501-1511.

Falk, A., \& Fischbacher, U. (2006). A theory of reciprocity. Games and Economic Behavior, 54(2), 293-315.

Fehr, E., \& Fischbacher, U. (2002). Why social preferences matter - The impact of non-selfish motives on competition, cooperation and incentives. Economic Journal, 112(478), C1C33.

Fehr, E., \& Gächter, S. (2000). Fairness and retaliation: The economics of reciprocity. Journal of Economic Perspectives, 14(3), 159-181.

Fischbacher, U. (2007). z-Tree: Zurich toolbox for ready-made economic experiments. Experimental Economics, 10(2), 171-178. 
Forgas, J. P. (1991). Affect and social judgments: An introductory review. In J. P. Forgas (Ed.), Emotion and social judgments (pp. 3-30). Elmsford, NY: Pergamon Press.

Frederick, S., Loewenstein, G. (1999) Hedonic Adaptation. In D. Kahneman, E. Diener \& N. Schwartz (Eds.) Well-being: The foundations of hedonic psychology. (pp. 302-329). New York, NY: Russell Sage Foundation.

Frijda, N. (1988). The laws of emotion. American Psychologist, 5, 349-58.

Gneezy, U., \& Güth, W. (2003). On competing rewards standards - An experimental study of ultimatum bargaining. Journal of Socio-Economics, 31(6), 599-607.

Greenberg, J. (1990). Employee theft as a reaction to underpayment inequity: The hidden cost of pay cuts. Journal of Applied Psychology, 75(5), 561-568.

Grimm, V., \& Mengel, F. (2011). Let me sleep on it: Delay reduces rejection rates in ultimatum games. Economic Letters, 111(2), 113-115.

Güth, W., Schmittberger, R., \& Schwarze, B. (1982). An experimental analysis of ultimatum bargaining. Journal of Economic Behavior and Organization, 3(4), 367-388.

Harlé, K. M. \& Sanfey, A. G. (2007). Incidental sadness biases social economic decisions in ultimatum game. Emotion, 7(4), 876-881.

Kagel, J. H., Kim, C., \& Moser, D. (1996). Fairness in ultimatum games with asymmetric information and asymmetric payoffs. Games and Economic Behavior, 13(1), 100-110.

Kahneman, D., Knetsch, J. L., \& Thaler, R. H. (1990). Experimental tests of the endowment effect and the Coase theorem. Journal of Political Economy, 98(6), 1325-1348.

Kahneman, D., \& Tversky, A. (1979). Prospect theory: An analysis of decision under risk. Econometrica, 47(2), 263-291.

King-Casas, B., Tomlin, D., Anen, C., Camerer, C. F., Quartz, S. R., \& Montague, P. R. (2005). Getting to know you: Reputation and trust in a two-person economic exchange. Science, 308, 78-83.

Kube, S., Marechal, M., \& Puppe, C. (2010). Do wage cuts damage work morale: Evidence from a natural field experiment. Unpublished manuscript. Retrieved from http://papers.ssrn.com/sol3/papers.cfm?abstract_id=1547823

Lawler, E. J. (2001). An affect theory of social exchange. American Journal of Sociology, 107(2), 321-352.

Lawler, E. J., \& Yoon, J. (1998). Network structure and emotion in exchange relations. American Sociological Review, 63(6), 871-894.

Mellers, B., Schwartz, A., \& Ritov, I. (1999). Emotion-based choice. Journal of Experimental Psychology: General, 128(3), 332-345.

Oechssler, J., Roider, A., \& Schmitz, P. W. (2008). Cooling-off in negotiations - Does it work? Unpublished manuscript. Retrieved from http://www.awi.uniheidelberg.de/with2/theorie2/ors_ultimatum.pdf

Oxoby, R. J., \& McLeish, K. N. (2004). Sequential decision and strategy vector methods in ultimatum bargaining: evidence on the strength of other-regarding behavior. Economic Letters, 84(3), 399-405.

Pillutla, M. M., \& Murnighan, J. K. (1996). Unfairness, anger, and spite: Emotional rejections of ultimatum offers. Organizational Behavior and Human Decision Processes, 68(3), 208224. 
Robinson, M. D., \& Clore, G. L. (2001). Simulation, scenarios, and emotional appraisal: testing the convergence of real and imagined reactions to emotional stimuli. Personality and Social Psychology Bulletin, 27(11), 1520-1532.

Rubinstein, A. (2008). Instinctive and cognitive reasoning: A study of response times. The Economic Journal, 117(523), 1243-1259.

Sanfey, A. G., Rilling, J. K., Aronson, J. A., Nystrom, L. E., \& Cohen, J. D. (2003). The neural basis of economic decision-making in the ultimatum game. Science, 300, 1755-1758.

Schneider, W., \& Shiffrin, R. M. (1977). Controlled and automatic human information processing: I. Detection, search, and attention. Psychological Review, 84(1), 1-66.

Shiffrin, R. M., \& Schneider, W. (1977). Controlled and automatic human information processing: II. Perceptual learning, automatic attending, and a general theory. Psychological Review, 84(2), 127-190.

Stanovich, K. E., \& West, R. F. (2000). Individual differences in reasoning: Implications for the rationality debate? Behavioral and Brain Sciences, 23(5), 645-726.

Strahilevitz, M. A., \& Loewenstein, G. (1998). The effect of ownership history on the valuation of objects. Journal of Consumer Research, 25, 276-289.

Thaler, R. (1980). Toward a positive theory of consumer choice. Journal of Economic Behavior and Organization, 1(1), 39-60.

Thompson, L., \& Loewenstein, G. (1992). Egocentric interpretations of fairness and interpersonal conflict. Organizational Behavior and Human Decision Processes, 51(2), 176-197.

Tidd, K. L., \& Lockard, J. S. (1978). Monetary significance of the affiliative smile: A case for reciprocal altruism. Bulletin of the Psychonomic Society, 11(6), 344-346.

Van Huyck, J. B., Battalio, R. C., \& Walters, M. F. (1995). Commitment versus discretion in the peasant-dictator game. Games and Economic Behavior, 10(1), 143-170. 
Table 1. Summary of means for Experiment 1 (IG)

\begin{tabular}{|c|c|c|c|c|}
\hline & \multicolumn{2}{|c|}{ Immediate treatment } & \multicolumn{2}{|c|}{ Delay treatment } \\
\hline & Sender & Responder & Sender & Responder \\
\hline \multicolumn{5}{|l|}{ Investment Game } \\
\hline Amount sent (\$) & $2.41(1.66)$ & & $2.63(1.67)$ & \\
\hline Amount returned (\$) & & $1.76(2.56)$ & & $1.81(2.34)$ \\
\hline Proportion returned & & $0.24(0.19)^{\mathrm{a}}$ & & $0.23(0.22)^{\mathrm{a}}$ \\
\hline Earnings (\$) & $4.35(2.15)$ & $10.47(4.16)$ & $4.19(2.26)$ & $11.06(4.58)$ \\
\hline \multicolumn{5}{|l|}{ Delay Activities } \\
\hline Email & 0.47 & 0.82 & 0.44 & 0.50 \\
\hline School work & 0.24 & 0.18 & 0.19 & 0.13 \\
\hline Drink & 0.00 & 0.06 & 0.13 & 0.00 \\
\hline Eat & 0.00 & 0.06 & 0.06 & 0.00 \\
\hline Listen to music & 0.06 & 0.00 & 0.06 & 0.00 \\
\hline Plan/organize schedule & 0.12 & 0.29 & 0.19 & 0.25 \\
\hline Recreational reading & 0.06 & 0.24 & 0.06 & 0.06 \\
\hline School reading & 0.12 & 0.06 & 0.06 & 0.19 \\
\hline Rest & 0.24 & 0.06 & 0.13 & 0.38 \\
\hline Surf the internet & 0.53 & 0.59 & 0.44 & 0.50 \\
\hline Think about the game & 0.35 & 0.35 & 0.31 & 0.56 \\
\hline Other & 0.12 & 0.24 & 0.13 & 0.06 \\
\hline \multicolumn{5}{|l|}{ Demographics } \\
\hline Age & $20.35(2.67)$ & $22.24(7.48)$ & $26.94(15.41)$ & $20.38(1.86)$ \\
\hline Gender (Male) & 0.53 & 0.47 & 0.44 & 0.50 \\
\hline
\end{tabular}

Note. Numbers in parentheses are standard errors.

${ }^{a}$ This statistic was computed for responders whose senders sent a non-zero amount of money. 
Table 2. Relationship of sender and responder behavior to treatment and demographics for Experiment 1 (IG)

\begin{tabular}{lccc}
\hline Model: & \multicolumn{2}{c}{ OLS } \\
Player: & Sender & \multicolumn{2}{c}{ Responder } \\
Dependent variable: & Amount sent & \multicolumn{2}{c}{ Amount returned } \\
& $(1)$ & $(2)$ & $(3)$ \\
\hline Amount received & & $0.277^{* *}$ & $0.280^{*}$ \\
& & $(0.132)$ & $(0.136)$ \\
Delay treatment & -0.333 & & -0.160 \\
& $(0.626)$ & & $(0.957)$ \\
Age & -0.017 & 0.256 & 0.255 \\
& $(0.028)$ & $(0.226)$ & $(0.760)$ \\
Gender (Male) & 0.117 & -0.711 & -0.723 \\
& $(0.598)$ & $(0.957)$ & $(0.980)$ \\
Constant & 2.689 & -5.202 & -5.132 \\
& $(0.773)$ & $(4.844)$ & $(4.966)$ \\
\hline Number of observations & 33 & 27 & 27 \\
$\mathrm{R}^{2}$ & 0.017 & 0.189 & 0.190 \\
\hline
\end{tabular}

Note. Numbers in parentheses are standard errors of parameter estimates; Models 2 and 3 include only data from responders who received positive amounts.

${ }^{*} p<0.1,{ }^{* *} p<0.05,{ }^{* * *} p<0.01$, all two-tailed 
Table 3. Summary of means for Experiment 2 (UG)

\begin{tabular}{lccccc}
\hline & \multicolumn{2}{c}{ Immediate treatment } & & \multicolumn{2}{c}{ Delay treatment } \\
\cline { 2 - 3 } \cline { 5 - 6 } & Proposer & Responder & & Proposer & Responder \\
\hline Ultimatum Game & & & & & \\
Chips offered & $43.50(22.94)$ & & & $45.81(18.76)$ & \\
Reject & & 0.41 & & & 0.14 \\
Earnings (\$) & $4.04(4.05)$ & $1.61(1.55)$ & & $6.43(3.47)$ & $2.14(1.16)$ \\
Delay Activities & & & & & \\
Email & 0.68 & 0.55 & & 0.38 & 0.43 \\
School work & 0.05 & 0.18 & & 0.05 & 0.19 \\
Drink & 0.09 & 0.05 & & 0.00 & 0.10 \\
Eat & 0.00 & 0.00 & & 0.00 & 0.00 \\
Listen to music & 0.05 & 0.09 & & 0.00 & 0.05 \\
Plan/organize schedule & 0.32 & 0.27 & & 0.14 & 0.10 \\
Recreational reading & 0.23 & 0.18 & & 0.10 & 0.29 \\
School reading & 0.05 & 0.18 & & 0.19 & 0.10 \\
Rest & 0.18 & 0.36 & & 0.24 & 0.10 \\
Surf the internet & 0.64 & 0.55 & & 0.62 & 0.43 \\
Think about the game & 0.59 & 0.55 & & 0.29 & 0.62 \\
Other & 0.14 & 0.09 & & 0.14 & 0.10 \\
Demographics & & & & & \\
Age & $20.18(4.27)$ & $20.18(2.13)$ & $21.19(4.37)$ & $20.67(3.76)$ \\
Male & 0.45 & 0.50 & 0.43 & 0.29 \\
\hline
\end{tabular}

Note. Numbers in parentheses are standard errors. 
Table 4. Relationship of proposer and responder behavior to treatment, demographics for Experiment 2 (UG)

\begin{tabular}{lccc}
\hline $\begin{array}{l}\text { Model: } \\
\text { Player: }\end{array}$ & $\begin{array}{c}\text { OLS } \\
\text { Proposer }\end{array}$ & \multicolumn{2}{c}{ Probit (marginal effects) } \\
Dependent variable: & Chips offered & Probability of rejection \\
& $(1)$ & $(2)$ & $(3)$ \\
\hline Chips offered & & $-0.014^{* * *}$ & $-0.014^{* * *}$ \\
& & $(0.004)$ & $(0.004)$ \\
Delay & 1.772 & & $-0.296^{* *}$ \\
& $(6.582)$ & & $(0.143)$ \\
Age & 0.556 & -0.014 & -0.007 \\
& $(0.818)$ & $(0.022)$ & $(0.022)$ \\
Gender (Male) & 0.881 & -0.024 & -0.102 \\
& $(6.948)$ & $(0.141)$ & $(0.139)$ \\
Constant & $31.886^{*}$ & & 43 \\
& $(16.405)$ & & -15.23 \\
\hline Number of observations & 43 & 43 & 0.402 \\
Log likelihood & & -17.41 & \\
(Pseudo) R & 0.018 & 0.316 & \\
\hline
\end{tabular}

Note. Numbers in parentheses are standard errors of parameter estimates. When restricted to unequal monetary divisions (less than 75 chips offered), chips offered and delay remain significant. When restricted to unequal chip divisions (less than 50 chips offered), chips offered is directionally consistent but not significant and delay is significant at $\alpha=0.10$.

${ }^{*} p<0.1,{ }^{* *} p<0.05,{ }^{* * *} p<0.01$, all two-tailed 
Table 5. Summary of means for Experiment 3 (UG)

\begin{tabular}{|c|c|c|c|c|}
\hline & \multicolumn{2}{|c|}{ Immediate treatment } & \multicolumn{2}{|c|}{ Delay treatment } \\
\hline & Proposer & Responder & Proposer & Responder \\
\hline \multicolumn{5}{|l|}{ Ultimatum Game } \\
\hline Chips offered & $44.01(2.51)$ & & $50.00(2.56)$ & \\
\hline Reject & & 0.42 & & 0.25 \\
\hline Earnings (\$) & $1.68(0.08)$ & $0.44(0.03)$ & $1.50(0.08)$ & $0.50(0.26)$ \\
\hline \multicolumn{5}{|c|}{ Reflective Processing } \\
\hline Word Count & & $16.35(1.32)$ & & $20.33(1.75)$ \\
\hline \multicolumn{5}{|l|}{ Emotions } \\
\hline Angry & & $2.48(0.18)$ & & $2.26(0.18)$ \\
\hline Frustrated & & $2.75(0.21)$ & & $2.63(0.20)$ \\
\hline Insulted & & $3.00(0.23)$ & & $2.77(0.21)$ \\
\hline Disappointed & & $3.63(0.22)$ & & $2.95(0.22)$ \\
\hline Happy & & $3.49(0.21)$ & & $3.75(0.21)$ \\
\hline Grateful & & $3.41 \quad(0.21)$ & & $3.51(0.22)$ \\
\hline Satisfied & & $3.43(0.21)$ & & $4.18(0.22)$ \\
\hline Confident & & $4.19(0.21)$ & & $4.08(0.22)$ \\
\hline Shocked & & $2.73(0.21)$ & & $2.36(0.18)$ \\
\hline Surprised & & $3.56(0.22)$ & & $3.11(0.20)$ \\
\hline \multicolumn{5}{|l|}{ Demographics } \\
\hline Age & $28.50(1.02)$ & $29.24(1.19)$ & $29.21(1.10)$ & $28.18(0.95)$ \\
\hline Male & 0.45 & 0.56 & 0.43 & 0.50 \\
\hline
\end{tabular}

Note. Numbers in parentheses are standard errors. 
Table 6. Relationship of proposer and responder behavior to treatment, demographics, reflective processing and emotions for Experiment 3 (UG)

\begin{tabular}{|c|c|c|c|c|c|c|}
\hline \multirow{4}{*}{$\begin{array}{l}\text { Model: } \\
\text { Player: } \\
\text { Dependent } \\
\text { variable: }\end{array}$} & OLS & \multicolumn{5}{|c|}{ Probit (marginal effects) } \\
\hline & Proposer & \multicolumn{5}{|c|}{ Responder } \\
\hline & Chips & \multicolumn{5}{|c|}{ Probability of rejection } \\
\hline & (1) & (2) & (3) & (4) & (5) & (6) \\
\hline Chips offered & & $\begin{array}{l}-0.012 * * * \\
(0.019)\end{array}$ & $\begin{array}{l}-0.012 * * * \\
(0.002)\end{array}$ & $\begin{array}{l}-0.006^{* * *} \\
(0.002)\end{array}$ & $\begin{array}{l}-0.006^{* * *} \\
(0.002)\end{array}$ & $\begin{array}{l}-0.005 * * \\
(0.002)\end{array}$ \\
\hline Delay & $\begin{array}{c}6.049 * \\
(3.612)\end{array}$ & & $\begin{array}{l}-0.127 * \\
(0.075)\end{array}$ & $\begin{array}{l}-0.13 \\
(0.083)\end{array}$ & $\begin{array}{l}-0.130 \\
(0.083)\end{array}$ & \\
\hline Age & $\begin{array}{l}-0.143 \\
(0.184)\end{array}$ & $\begin{array}{c}0.000 \\
(0.004)\end{array}$ & $\begin{array}{l}-0.000 \\
(0.004)\end{array}$ & $\begin{array}{c}0.001 \\
(0.004)\end{array}$ & & \\
\hline Gender (Male) & $\begin{array}{c}0.549 \\
(3.618)\end{array}$ & $\begin{array}{l}-0.016 \\
(0.078)\end{array}$ & $\begin{array}{l}-0.027 \\
(0.078)\end{array}$ & $\begin{array}{l}-0.108 \\
(0.095)\end{array}$ & & \\
\hline Word Count & & & & $\begin{array}{l}-0.003 \\
(0.003)\end{array}$ & & \\
\hline Angry & & & & $\begin{array}{c}0.069 \\
(0.048)\end{array}$ & & \\
\hline Frustrated & & & & $\begin{array}{c}0.001 \\
(0.037)\end{array}$ & & \\
\hline Insulted & & & & $\begin{array}{c}0.076^{*} \\
(0.040)\end{array}$ & $\begin{array}{l}0.089 * * * \\
(0.034)\end{array}$ & $\begin{array}{l}0.060 * * * \\
(0.022)\end{array}$ \\
\hline Disappointed & & & & $\begin{array}{l}-0.085^{* *} \\
(0.040)\end{array}$ & $\begin{array}{l}-0.075^{* *} \\
(0.037)\end{array}$ & \\
\hline Happy & & & & $\begin{array}{l}-0.055 \\
(0.042)\end{array}$ & $\begin{array}{l}-0.063 \\
(0.039)\end{array}$ & \\
\hline Grateful & & & & $\begin{array}{l}-0.010 \\
(0.034)\end{array}$ & & \\
\hline Satisfied & & & & $\begin{array}{l}-0.080 * * \\
(0.040)\end{array}$ & $\begin{array}{l}-0.085^{* * *} \\
(0.039)\end{array}$ & $\begin{array}{l}-0.104 * * * \\
(0.028)\end{array}$ \\
\hline Confident & & & & $\begin{array}{c}0.076 * * \\
(0.031)\end{array}$ & $\begin{array}{l}0.065^{* *} \\
(0.028)\end{array}$ & $\begin{array}{l}0.057^{* *} \\
(0.025)\end{array}$ \\
\hline
\end{tabular}


Shocked

Surprised

Constant

$47.829 * * *$

(6.151)
$-0.025$

(0.044)

$\begin{array}{cc}0.036 & 0.039 \\ (0.030) & (0.025)\end{array}$

\begin{tabular}{|c|c|c|c|c|c|c|}
\hline $\begin{array}{l}\text { Number of } \\
\text { observations }\end{array}$ & 172 & 172 & 172 & 172 & 172 & 172 \\
\hline Log likelihood & & -86.78 & -85.39 & -65.57 & -67.59 & -72.44 \\
\hline (Pseudo) $\mathrm{R}^{2}$ & 0.018 & 0.211 & 0.223 & 0.40 & 0.39 & 0.34 \\
\hline AIC & & 1.05 & 1.06 & 0.949 & 0.891 & 0.900 \\
\hline $\mathrm{BIC}$ & & -691.22 & -688.86 & -671.86 & -703.86 & -714.75 \\
\hline
\end{tabular}

Note. Numbers in parentheses are standard errors of parameter estimates. ${ }^{*} p<0.1,{ }^{* *} p<0.05,{ }^{* * *} p<0.01$, all two-tailed 
Table 7. Independent probit coefficients, relationship of probability of rejection to emotions and reflective processing with only treatment and demographic controls for Experiment 3 (UG)

\begin{tabular}{|c|c|c|}
\hline Model: & \multicolumn{2}{|c|}{ Probit (marginal effects) } \\
\hline Player: & \multicolumn{2}{|c|}{ Responder } \\
\hline Dependent Variable: & \multicolumn{2}{|c|}{ Probability of rejection } \\
\hline \multicolumn{3}{|l|}{ Reflective Processing } \\
\hline Word Count & -0.003 & $(0.003)$ \\
\hline \multicolumn{3}{|l|}{ Emotions } \\
\hline Angry & $0.088 * * *$ & $(0.025)$ \\
\hline Frustrated & $0.058 * * *$ & $(0.022)$ \\
\hline Insulted & $0.080 * * *$ & $(0.021)$ \\
\hline Disappointed & 0.032 & $(0.021)$ \\
\hline Happy & $-0.078 * * *$ & $(0.022)$ \\
\hline Grateful & $-0.050 * *$ & $(0.021)$ \\
\hline Satisfied & $-0.081 * * *$ & $(0.022)$ \\
\hline Confident & -0.004 & $(0.019)$ \\
\hline Shocked & $0.049 * * *$ & $(0.022)$ \\
\hline Surprised & 0.028 & $(0.020)$ \\
\hline
\end{tabular}

Note. Numbers in parentheses are standard errors of parameter estimates.

${ }^{*} p<0.1,{ }^{* *} p<0.05,{ }^{* * *} p<0.01$, all two-tailed 
Table 8. Relationship of reflective processing and emotions to study treatments and demographics for Experiment 3 (UG)

\begin{tabular}{|c|c|c|c|c|c|c|c|c|c|c|c|}
\hline \multirow{3}{*}{$\begin{array}{l}\text { Model: } \\
\text { Player: } \\
\text { Dependent } \\
\text { variable: }\end{array}$} & \multicolumn{11}{|c|}{ OLS } \\
\hline & & & & & & Responder & & & & & \\
\hline & $\begin{array}{l}\text { Word } \\
\text { Count }\end{array}$ & Angry & Frustrated & Insulted & $\begin{array}{c}\text { Dis- } \\
\text { appointed }\end{array}$ & Happy & Grateful & Satisfied & Confident & Shocked & Surprised \\
\hline $\begin{array}{l}\text { Chips } \\
\text { offered }\end{array}$ & $\begin{array}{c}0.011 \\
(0.047)\end{array}$ & $\begin{array}{l}-0.028 * * * \\
(0.005)\end{array}$ & $\begin{array}{l}-0.032 * * * \\
(0.006)\end{array}$ & $\begin{array}{l}-0.047 * * * \\
(0.006)\end{array}$ & $\begin{array}{l}-0.044 * * * \\
(0.006)\end{array}$ & $\begin{array}{l}0.035^{* * *} \\
(0.006)\end{array}$ & $\begin{array}{l}0.038^{* * *} \\
(0.006)\end{array}$ & $\begin{array}{l}0.041 * * * \\
(0.006)\end{array}$ & $\begin{array}{c}0.004 \\
(0.006)\end{array}$ & $\begin{array}{l}-0.010^{*(\mathrm{c})} \\
(0.006)\end{array}$ & $\begin{array}{l}0.011^{*(a)} \\
(0.006)\end{array}$ \\
\hline Delay & $\begin{array}{c}3.914 * \\
(2.226)\end{array}$ & $\begin{array}{l}-0.015 \\
(0.233)\end{array}$ & $\begin{array}{c}0.092 \\
(0.261)\end{array}$ & $\begin{array}{c}0.102 \\
(0.263)\end{array}$ & $\begin{array}{l}-0.450 * \\
(0.261)\end{array}$ & $\begin{array}{c}0.171 \\
(0.261)\end{array}$ & $\begin{array}{l}-0.029 \\
(0.264)\end{array}$ & $\begin{array}{c}0.546^{* *} \\
(0.266)\end{array}$ & $\begin{array}{l}-0.084 \\
(0.291)\end{array}$ & $\begin{array}{l}-0.319 \\
(0.270)\end{array}$ & $\begin{array}{l}-0.533^{*(a)} \\
(0.287)\end{array}$ \\
\hline Age & $\begin{array}{c}0.042 \\
(0.113)\end{array}$ & $\begin{array}{c}0.006 \\
(0.012)\end{array}$ & $\begin{array}{l}-0.013^{(b)} \\
(0.013)\end{array}$ & $\begin{array}{c}0.105 \\
(0.013)\end{array}$ & $\begin{array}{c}0.002 \\
(0.013)\end{array}$ & $\begin{array}{c}0.015 \\
(0.013)\end{array}$ & $\begin{array}{c}0.008 \\
(0.014)\end{array}$ & $\begin{array}{c}0.006 \\
(0.014)\end{array}$ & $\begin{array}{l}-0.006 \\
(0.015)\end{array}$ & $\begin{array}{l}-0.003 \\
(0.014)\end{array}$ & $\begin{array}{l}0.032^{* *(b)} \\
(0.015)\end{array}$ \\
\hline $\begin{array}{l}\text { Gender } \\
\text { (Male) }\end{array}$ & $\begin{array}{l}-0.779 \\
(2.26)\end{array}$ & $\begin{array}{l}0.659 * * * \\
(0.024)\end{array}$ & $\begin{array}{l}0.532 * * \\
(0.265)\end{array}$ & $\begin{array}{c}0.252 \\
(0.267)\end{array}$ & $\begin{array}{c}0.328 \\
(0.265)\end{array}$ & $\begin{array}{c}0.470^{*} \\
(0.264)\end{array}$ & $\begin{array}{l}0.658^{* *} \\
(0.267)\end{array}$ & $\begin{array}{c}0.246 \\
(0.270)\end{array}$ & $\begin{array}{c}0.424 \\
(0.297)\end{array}$ & $\begin{array}{c}0.271 \\
(0.276)\end{array}$ & $\begin{array}{c}0.125 \\
(0.291)\end{array}$ \\
\hline Past Week & & $\begin{array}{l}0.136^{* *} \\
(0.068)\end{array}$ & $\begin{array}{l}0.136 * * \\
(0.065)\end{array}$ & $\begin{array}{l}0.167 * * \\
(0.075)\end{array}$ & $\begin{array}{l}0.247 * * * \\
(0.070)\end{array}$ & $\begin{array}{l}0.279 * * * \\
(0.079)\end{array}$ & $\begin{array}{l}0.287 * * * \\
(0.074)\end{array}$ & $\begin{array}{l}0.224 * * * \\
(0.083)\end{array}$ & $\begin{array}{l}0.422 * * * \\
(0.087)\end{array}$ & $\begin{array}{l}0.294 * * * \\
(0.081)\end{array}$ & $\begin{array}{l}0.271 * * * \\
(0.077)\end{array}$ \\
\hline Constant & & $\begin{array}{l}2.751 * * * \\
(0.513)\end{array}$ & $\begin{array}{l}3.743 * * * \\
(0.575)\end{array}$ & $\begin{array}{l}4.212^{* * *} \\
(0.571)\end{array}$ & $\begin{array}{l}4.612^{* * *} \\
(0.571)\end{array}$ & $\begin{array}{l}-0.202 \\
(0.635)\end{array}$ & $\begin{array}{l}-0.218 \\
(0.597)\end{array}$ & $\begin{array}{c}0.241 \\
(0.606)\end{array}$ & $\begin{array}{c}2.000 \\
(0.646)\end{array}$ & $\begin{array}{c}2.468 \\
(0.563)\end{array}$ & $\begin{array}{c}1.215 \\
(0.606)\end{array}$ \\
\hline $\begin{array}{l}\text { Number of } \\
\text { obs. } \\
\text { Adj } R^{2}\end{array}$ & & 172 & 172 & $\begin{array}{r}172 \\
0.31\end{array}$ & $\begin{array}{r}172 \\
0.32\end{array}$ & 172 & $\begin{array}{r}172 \\
0.27\end{array}$ & $\begin{array}{r}172 \\
0.31\end{array}$ & $\begin{array}{r}172 \\
0.14\end{array}$ & $\begin{array}{r}172 \\
0.10\end{array}$ & $\begin{array}{r}172 \\
0.11\end{array}$ \\
\hline
\end{tabular}

Note. Numbers in parentheses are standard errors of parameter estimates. "Past Week" refers to the reported feeling of the same emotions during past week. All significance levels similar in the ordered logit, except as notated: ${ }^{(a)}$ not significant under ordered logit, (b) $p<0.1$ under ordered probit, ${ }^{\text {(c) }} \mathrm{p}<0.05$ under ordered probit.

${ }^{*} p<0.1,{ }^{* *} p<0.05,{ }^{* * *} p<0.01$, all two-tailed 
(A)

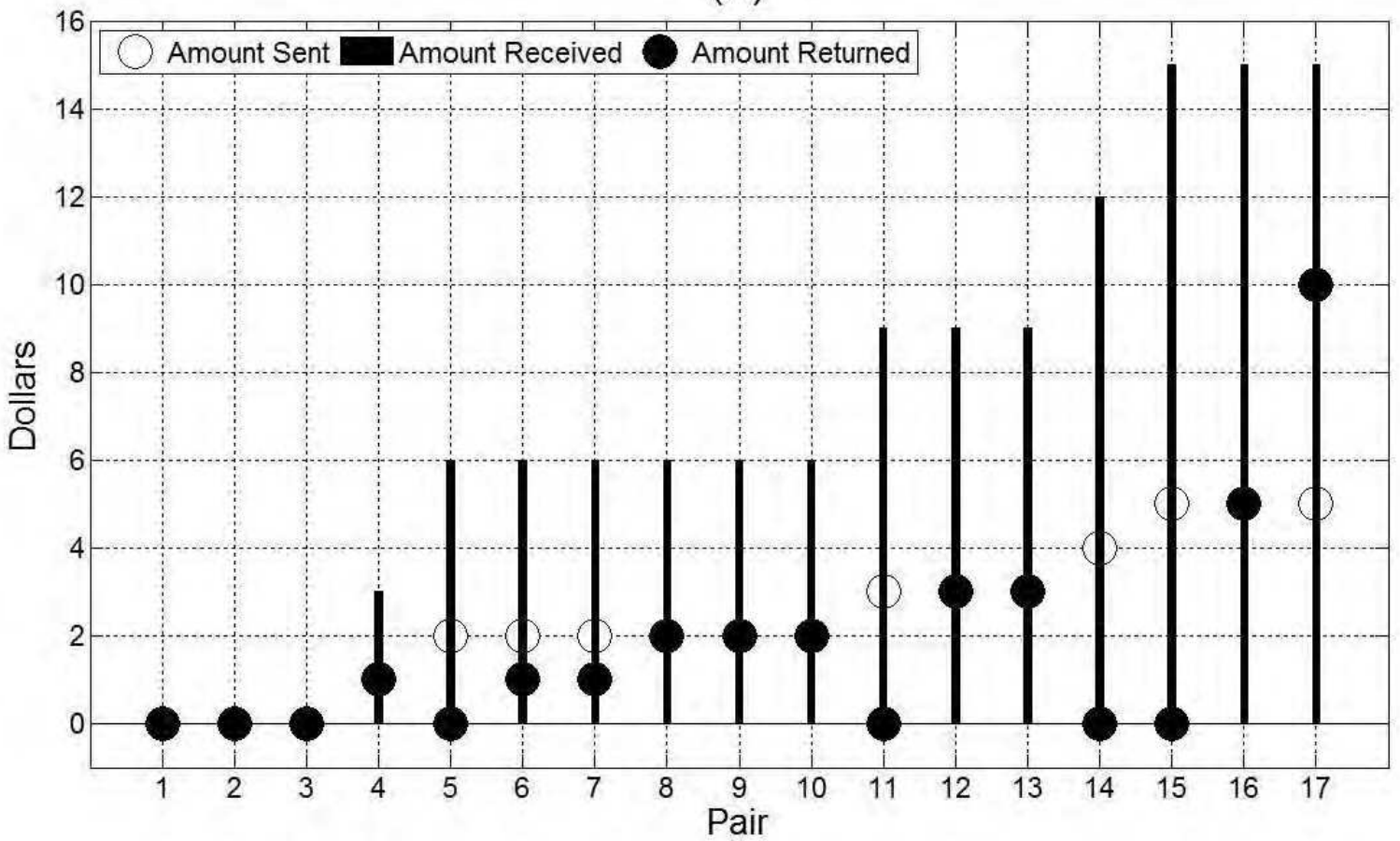

(B)

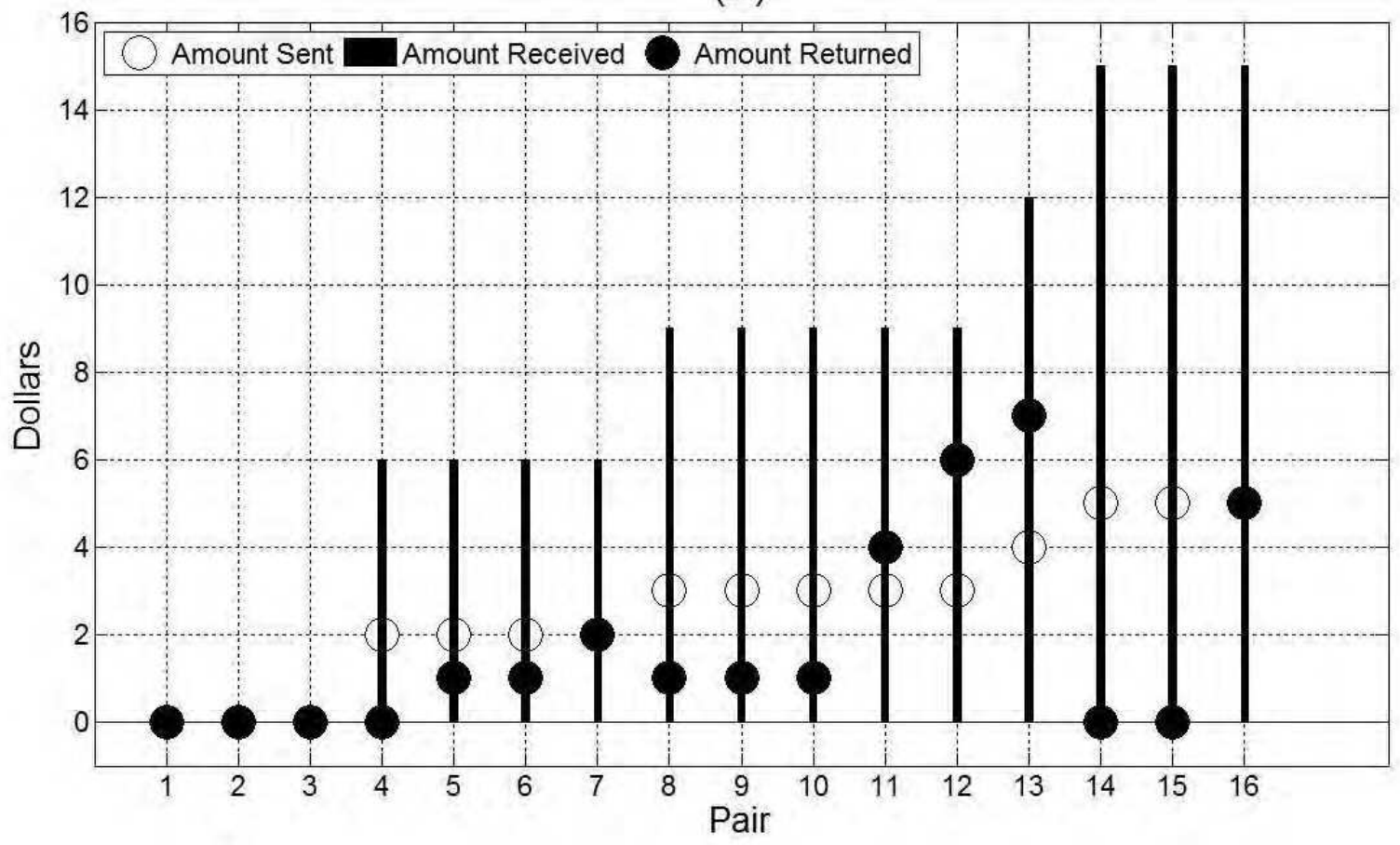

Figure 1. Amount sent, received, and returned per sender-responder pair in the (A) Immediate and (B) Delay treatments of the investment game. 
(A)

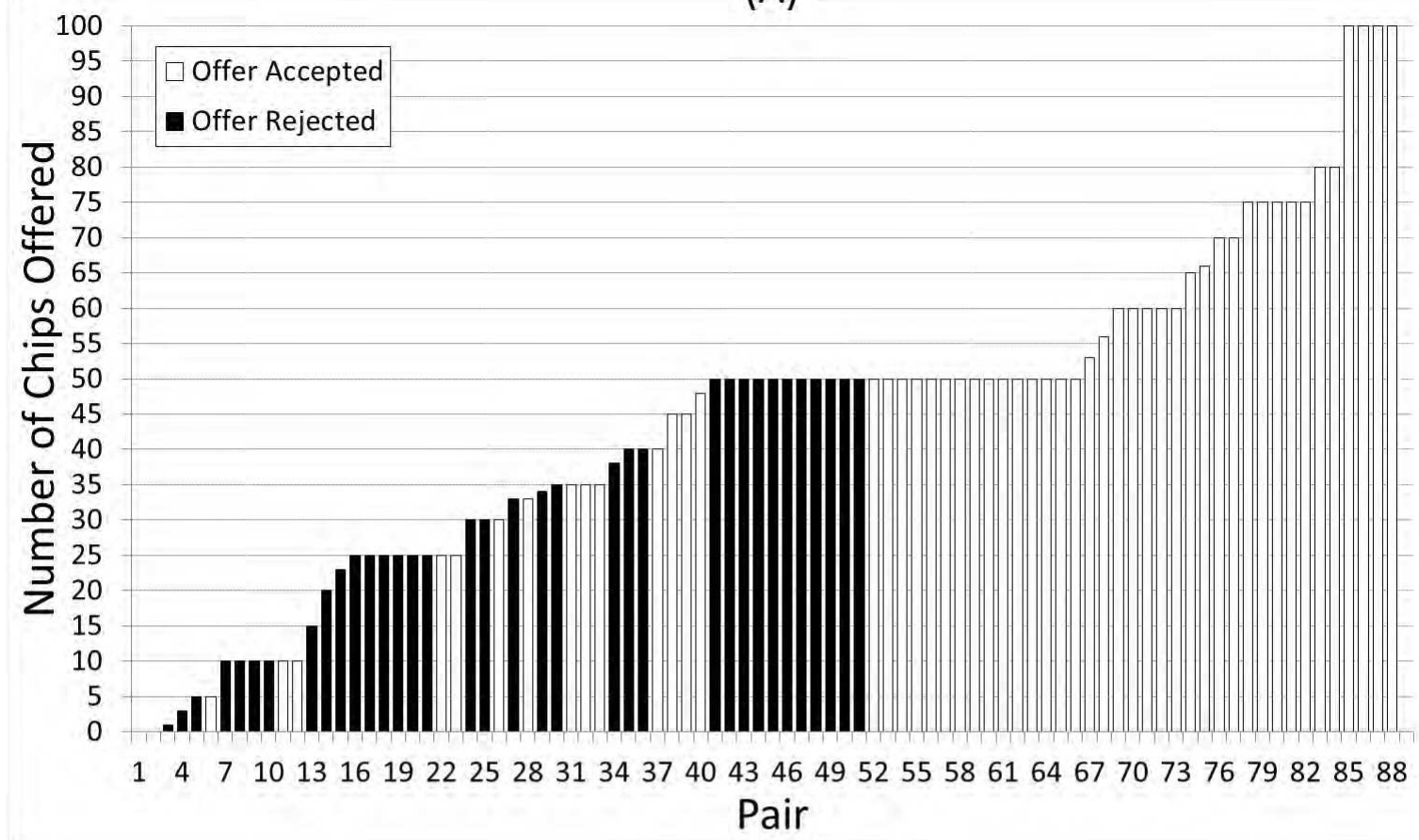

(B)

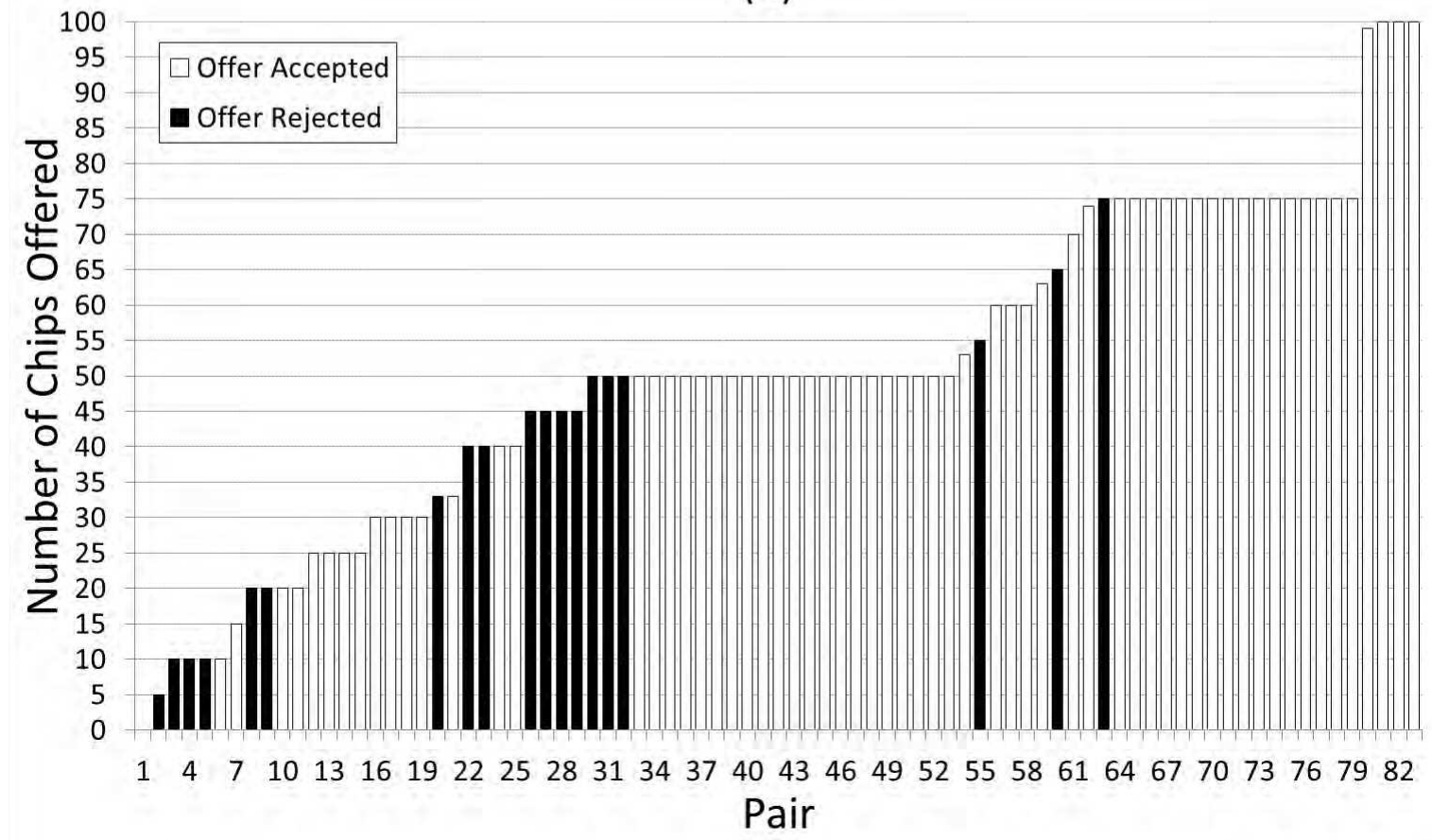

Figure 3. Number of chips offered and accept/reject decision per proposer-responder pair in the (A) Immediate and (B) Delay treatments of the ultimatum game. 